\title{
RECENT FINDINGS ON THE IMPAIRMENT OF AIRMANSHIP BY ALCOHOL
}

Stanley R. Mohler, M.D.

Approved by

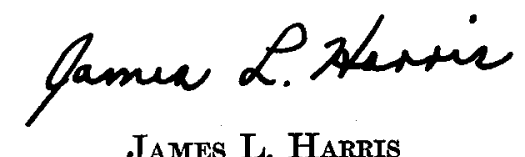

James L. Harris

Chrief, Aeromedical Education DrvisIoN
Released by

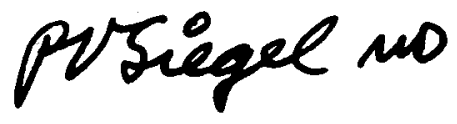

P. V. Steger, M.D. Federal AIr Surgeon

September 1966

FEDERAL AVIATION AGENCY

Office of Aviation Medicine 
Qualified requestors may obtain Aviation Medical Reports from Defense Documentation Center. The general public may purchase from Clearinghouse for Federal Scientific and Technical Information, U.S. Dept. of Commerce, Springfield, Va. 22151 


\title{
RECENT FINDINGS ON THE IMPAIRMENT OF AIRMANSHIP BY ALCOHOL
}

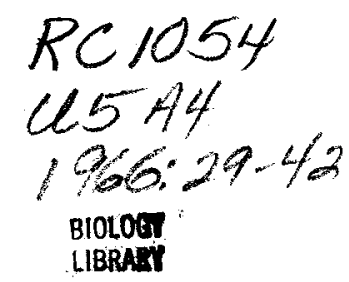

\author{
Stanley R. Mohler, M.D.*
}

\section{Introduction}

Evidence indicates that ethyl alcohol was associated in 1963 with one-third of the fatal general aviation accidents. ${ }^{4}$ An aggressive airman education program on these findings appears to represent a major means of accomplishing a significant dent in the accident rate.

Does ethyl alcohol in small quantities really impair airmanship? Many people apparently get away with driving and drinking - cannot they do so with flying? To find answers to these questions, the following studies and analyses have been undertaken.

"Taking one for the road" became a tradition in the horse and carriage era of transportation. The indications are that no significant increase in the accident rate accompanied this practice (although the statistics are sketchy). Also, it was helpful that the horse had no blood alcohol level.

As the automobile came into being during the early twentieth century, a carryover occurred with respect to the custom of driving in various states of intoxication. Physicians and law-enforcement officers began to see an apparent relationship between alcohol and driving accidents, but conflicting experiences clouded the picture.

As pointed out by Dr. Wolfgang Schmidt and his colleagues, a great deal of confusion has resulted because of a failure on the part of investigators to differentiate between (1) the impairing effects of alcohol on proficiency with respect to a given task, and (2) the character of the individual who drinks alcohol sufficiently to be clasified as an alcoholic. ${ }^{1}$ This paper is concerned with the degree of short term impairment which follows the recent consumption of alcohol.

* Dr. Mohler is Chlef, Aeromedical Applications Division Office of Aviation Medicine, Federal Aviation Agency, Washington, D.C.
The following information represents an attempt to summarize the present knowledge with respect to the significance of alcohol as a precipitant or predisposing factor in light aircraft accidents. The physician, flight surgeon, and aviation educator, armed with the facts, can serve more effectively in their respective roles as promoters of flight safety and improved public health.

\section{Base-line Knowledge}

A survey of the general driving population of one large community revealed that 23 percent of the persons involved in automobile accidents had blood alcohol levels of varying amounts. ${ }^{2}$ Studies in other communities have indicated both higher and lower proportions of automobile accidents involving alcohol. A true assessment of the role of ethyl alcohol in vehicular accidents is often complicated by (1) incomplete investigations of many accidents, (2) absence of blood or breath alcohol determinations, (3) lack of accurate "nonalcohol" involved accident data for a given environment, and (4) undetermined operator characteristics (non-alcoholic, alcoholic, physically impaired, emotionally unstable, etc.).

Curiously, although De Saussure warned as early as 1786 that there is an incompatibility between enduring the low barometric pressure environment found on high mountains and the consumption of wine or liquor, two balloonists of the era thought otherwise. ${ }^{3}$ Robertson ascended in a balloon from Hamburg in 1803, and upon reaching a height equivalent to twelve inches of pressure (304.8 $\mathrm{mm} \mathrm{Hg}$, or roughly equivalent to 23,000 feet), records that only with the aid of a little fortifying wine did he succeed in "finding intervals of mental clarity and power". The same year, Zambeccari and two colleagues ascended from Bologna, and reported that at high altitude two of the aeronauts fell in a torpor, 
while the third, who, among other things, had "drunk rum abundantly" was the only one who remained awake.

It becomes apparent that traveling through the air beneath a balloon is a matter considerably removed in complexity from traveling by other means. The balloonist has control of one parameter of his vehicle: the vertical dimension, and the time parameter is essentially that bounded by the speed of the wind. Of course, the passive balloonist, usually not called upon for great physical exertion "at altitude", would not notice the effects of alcohol as soon as the mountain climbers described by $\mathrm{De}$ Saussure.

Similarly, it is clear that when great-grandfather climbed into his buggy and started out across the countryside, he delegated a fair share of the operator task to the horse, which, as previously mentioned, had no blood alcohol level.

It is not uncommon for yachtsmen to habitually drink while piloting their craft, apparently with a fairly respectable degree of safety. In the following sections, the task of yachting, will be compared with that of driving, and, subsequently, with that of flying. First, a brief presentation of pertinent considerations relative to alcohol in the context of this paper will be made.

\section{Relevant Considerations}

In the recent analysis covering 1963, startling information concerning the extent to which alcohol is associated with fatal light airplane accidents is revealed. ${ }^{4}$ The authors, who operated the Fedral Aviation Agency's medical investigation program relative to U.S. civil aircraft accidents, have found that for the year 1963 there were 477 general aviation fatal accidents in which 899 persons died (the term general aviation encompasses all civilian private, business, corporate and commercial flying, excluding air lines operations-scheduled and unscheduled).

The above study shows that toxicological examinations were performed on the pilots involved in 158 of these accidents. Fifty six, or 35.4 percent, of the examinations showed $15 \mathrm{mg} \%$ (15 milligrams alcohol per 100 milliliters of blood, or 0.015 percent) or higher blood or tissue ethyl alcohol concentrations. The average blood alcohol for the group was $145 \mathrm{mg} \%$ (0.145 percent).

As the authors point out, this is the first time that objective evidence indicates that one-third of the fatal accidents in general aviation are associated with alcohol. Due to the absence of alcohol determinations, they excluded ten fatal accidents where the history established alcohol as a key factor, and they also excluded cases where the examinations showed levels below $15 \mathrm{mg} \%$.

When four ounces of pure alcohol are consumed by an average man four hours prior to an accident, a blood alcohol level of $40 \mathrm{mg} \%$ (0.04 percent) or more will be found at the time of the accident. $^{1}$ Consequently, it appears from the above analysis that a significant number of general aviation pilots are undertaking to pilot aircraft shortly after indulging in alcohol, and that an aggressive airman education program regarding the incompatibility of alcohol and flying is indicated.

In 1962, the Federal Aviation Agency notified its five thousand Designated Aviation Medical Examiners that an analysis of general aviation accidents for the years 1957 to 1960 showed that forty to fifty percent of the accidents in which the investigation report mentioned alcohol were fatal, while only ten percent of the accidents in which alcohol was not mentioned were fatal. ${ }^{5}$

Dr. McFarland has pointed out that over ninety percent of the ingested alcohol is metabolized at a fixed rate by the liver, and that if 163 grams of ethyl alcohol are rapidly ingested (equivalent to 5.5 ounces of ethyl alcohol, 7-8 beers or 5 to 6 shots of whiskey), blood alcohol levels will reach more than $250 \mathrm{mg} \%$ in about two hours.11 Even eighteen hours later, the declining blood alcohol will still be in the $50 \mathrm{mg} \%$ range. Taking the same amount of alcohol over a four hour period will result in a lower peak blood alcohol level (220 $\mathrm{mg} \%$ at four hours), but the eighteen hour blood alcohol level will be almost the same as noted above, due to its fixed rate of metabolism by the liver.

Dr. Herman Heise has reported to the Flying Physicians' Association that individuals tested for judgment, sensory and motor functions, prior to and shortly after the consumption of alcohol, showed deterioration at blood alcohol levels in the range of $50 \mathrm{mg} . \% .^{7}$ Two shots (two ounces) of whiskey or two beers will produce a $50 \mathrm{mg} \%$ blood alcohol level in a 150 pound man.

He also stresses the fact that the potential after effects of alcohol, as found 24 hours later (hangover, nystagmus*, etc.), can be detrimental to flying, and discusses the interesting finding in 92 post mortem examinations of Swedish Air Force

\footnotetext{
* Involuntary oscillation of the eye balls.
} 
pilots who were involved in accidents, that 47 had no blood alcohol level, 18 were doubtful, 14 had a small trace, and 13 had levels of measurable degrees.

Interestingly, the flight surgeons' guide for the First World War, contains only the briefest mention of the harmful effects of alcohol on flying ("how foolish it is to go up in an aeroplane not only in a condition of drunkenness, but even in a state of excitation, which may falsify your sensations and predispose you to foolish action"statement by the French Flight Surgeon, Dr. Guilbert, p. 130).$^{8}$ A later text of aviation medicine contained essentially no reference to alcohol and flying, either as a potential problem or a factor in accidents. ${ }^{9}$ A text published a little later, however, devoted several pages to the subject. ${ }^{10}$

It became apparent in the 1940's that the additive and synergistic effects of alcohol on impairment when combined with various factors such as fatigue, drugs, hypoxia, illnesses, etc., were quite marked. Dr. McFarland points out that Committees of the American Medical Association and the National Safety Council have concluded that drinking drivers may be divided into three rough groups with respect to impairment:

1. Up to $50 \mathrm{mg} \%$ blood al-

cohol --_.._-_..-- for driving, the finding is ( $2 \mathrm{oz}$. whiskey or 2 bottles inconclusive.

of beer)

2. $50 \mathrm{mg} \%$ to $150 \mathrm{mg} \%$... for driving violations, the ( 6 oz. whiskey or 6 bottles finding is relevant to of beer) prosecution.

3. $150 \mathrm{mg} \%$ and higher --- the finding is clear cut evidence that driving behavior is significantly in fluenced by drinking.

Illustration One presents the table used by Dr. Kurt M. Dubowski, Director of Clinical Chemistry and Toxicology, of the University of Oklahoma Medical Center, in assessing the impairment of drivers at given blood alcohol levels.

It should be noted that this table is based on the adult, neither aged nor ill, whose size is in 150 pound range, and who is neither an habitual - drinker nor an alcoholic. It also assumes that the individual is not fatigued or preoccupied by heavy mental or emotional burdens.

\section{Analysis of the Flying Task}

Illustration Two provides a diagram of certain of the key factors involved in piloting a light aircraft. These include roll, pitch and yaw movements. There are such matters as "velocity never exceed", stalling speeds, drift movements, gusts, and critical attitudes. The automobile presents an extremely simplified control picture with respect to the above points (as a matter of fact, under most driving conditions, the automobile has none of these considerations).

In addition, the light plane pilot must navigate, must make appropriate control settings, must coordinate, and must make critical adjustments of the power, trim, mixture, propeller, etc., prior to take-off, during climb, en route, during descent, and when landing. $\mathrm{He}$ must exercise proper judgments concerning "go" or "no go" in different situations, a matter seriously compromised by the effects of alcohol on the cerebrum and on the emotional mechanisms.

The pilot must operate the aircraft in the air at speeds many times those used by cars. When he changes the position of one control, almost certainly all of the other controls will be affected. Weather factors in flying are far more crtical than is the case with autos, and pilots must also calculate how the barometric pressure and the air temperature will influence his plane's lifting capabilities at given airfield lengths and with given weight loadings.

Visibility factors concerned with haze, dust, rain or darkness, icing problems, and the occurrence of the unanticipated (head winds, fuel shortage, engine or radio malfunction, etc.), must be dealt with quickly, correctly, and skillfully. The leeway concerning these factors for the automobile driver, as compared to the airplane pilot, is great. In addition, automobiles have yet to become involved in airport and en route radio procedures.

Owners handbooks for typical light singleengine and four-place retractable-gear aircraft, show 20 different pre-flight categories of items to check out, 5 specific starting maneuvers, 10 ground check operations, 10 pre-take-off checks, 7 climb operations, 10 categories of en route operations, 7 prelanding operations, 3 landing operations, and 8 shut-down categories of items. This bare minimum of 80 essential items, all of which must be individually ascertained to ensure a successful flight accomplished with a reasonable level of safety, makes an interesting comparison with the 10 items listed in current automobile owner's manuals. 
Obviously, flying, as described above, is considerably more complicated than driving, and offers eight times or more the opportunity for error than is the case with driving.

The agile mind, unencumbered by alcohol, certain drugs, fatigue, or physical impairment, finds, through practice, that mastery of the above matters pertaining to safe flight is accomplished with surprising ease. However, as Dr. McFarland points out in the above reference, alcohol, even in small amounts, produces, among other things:

(1) A dulling of critical judgment;

(2) A decreased sense of responsibility;

(3) Diminished skill reactions and coordination;

(4) Decreased speed and strength of muscular reflexes (even after 1 ounce of alcohol);

(5) Twenty percent decrease in efficiency of eye movements during reading (after 1 ounce of alcohol);

(6) Significantly increased frequency of errors (after 1 ounce of alcohol);

(7) Constriction of visual fields;

(8) Decreased ability to see under dim illuminations;

(9) Loss of efficiency of sense of touch;

(10) Decrease of memory and reasoning ability ;

(11) Increased susceptibility to fatigue and decreased attention span;

(12) Decreased relevance of responses in free association tests, with an increase in nonsensical reactions ;

(13) Increased self confidence with decreased insight into immediate capabilities and mental and physical status.

Thus, it becomes clear that in view of the considerably increased complexity of flying over that of driving, the effects of alcohol will be more deleterious in the case of flying. In addition to the increased complexity of flying, flight also involves accelerations and decelerations around the roll, pitch and yaw axes, and in the horizontal, vertical and lateral directions, which stimulate the vestibular organs, the proprioceptive system and other systems. Proper interpretation (or proper disregard) for the sensations accompanying these accelerations must be made. Alcohol interferes with this interpretation.

It should be noted that in those aircraft simulators which do not produce g's, this critical factor in flight performance is not duplicated, a matter simplifying the task of "flying" the simulator, and requiring careful interpretation of alcohol studies conducted with simulators. It should also be noted that automobiles normally have accelerations which are under the control of the driver in the longitudinal and the lateral (turn) axes only. On icy or wet roads, yawing about the vertical axis may be a complicating control factor for drivers.

Critical to flying, is the effect of alcohol on the "latent deviation of the eyes" (heterophoria). A review of this subject reveals that with increasing levels of blood alcohol, orthophoric (normal eye muscle balance) individuals gradually become esophoric (tendency to be cross-eyed). ${ }^{12}$ Higher levels of alcohol produce esotropia (crosseyed) and a resulting diplopia (double vision) in the primary position. A deterioration of "motorfusion" reserve occurs, and nystagmus appears during, and remains long after (thirty six hours), alcohol consumption.

One interesting consideration to be briefly mentioned here, is that when a person undertakes to pilot an aircraft from a point on the surface of the earth, along a given course, to another point on the surface, hundreds of decisions must be made, some on the basis of incomplete information, some on the basis of unexpected information (adverse weather occurs, etc.). Proper maneuvers must be accomplished, and a return to the home station, or a landing at an alternative point may be judicious.

To a lesser extent, the above considerations apply also to local pleasure hops. The above facts mean that the flying task is amenable to treatment through the mathematical theory of games as developed in 1928 by John Von Neumann. ${ }^{16}$ Visual Flight Rules flying from uncontrolled fields represents a two party (duopolistic) game, in which one party is the pilot, and the opponent is represented by 'chance' and the 'laws of nature'. The essential feature of a game is the fact that the individual player has to do with one or more opponents, and that only some of the relevant variables are under the control of a given player. To win (assuming survival as a criteria of winning) the pilot has to return to the surface of the earth in an intact status.

Now, it can be readily seen that anything which impairs the pilot player's ability to make successive decisions will lead to an increased number of lost games (increased number of fatal acci- 
dents). As seen in the accident case described elsewhere in this paper, concerning an elderly pilot who flew into a field which was usually uncontrolled, but which had a temporary control tower in use on the day in question, unexpected "coalitions" can occur, as described in the theory of games, which can lead the pilot-player to lose if he doesn't make the right decision at the right time. In the case in question, the evidence indicates that the $35 \mathrm{mg} \%$ blood alcohol level was sufficient to decrease the pilot's ability to properly respond to the red signal which the tower, in 'coalition' with the elements, gave him-resultsa lost game.

The interesting thing about the study of games, is that statistics is not of the essence in game theory. Thus, potential flying hazards can be identified within the context of a given set of circumstances, obviating the necessity of experiencing a series of tragedies which, in retrospect, reveal what would be anticipated through game theory.

\section{Certain Accidents and Experiences}

It is worthy of note that in both World Wars, and during peace time, various pilots have accomplised amazing aerobatic maneuvers while under the influence of alcohol. Certain air mail pilots not infrequently undertook their scheduled flights in the 1920's following the consumption of considerable amounts of alcohol. ${ }^{13}$ However, warnings begin to be found in lay aviation books in the 1930's and early 1940's. In one book, the statement is made that alcohol is "really a very common" cause of aircraft accidents. ${ }^{14}$

In one midwest state and its nearby area, during the period bounded roughly by 1963 , half of the ten fatal light airplane accidents involved drinking pilots. ${ }^{15}$

One of these accidents involved a businessman who had consumed alcohol to the point that while he was flying locally, he had markedly slurred speech in his communications with the Flight Service Station personnel. He made repeated passes at a hard surfaced runway which was at least 4000 feet long, but, even with the assistance of these persons, was unable to land. He later had a fatal crash when the airplane ran out of fuel.

Another of these involved the suicide of a person who intentionally flew into a University building after announcing his plans to do so over
Unicom to the local airport. The pilot had long been troubled by emotional problems, and had, as revealed by post mortem, a blood alcohol level of $260 \mathrm{mg} \%$. This level is not infrequently associated with the production of emotions of rage and grief, and, in troubled individuals, can lead to violent actions accompanied by potential or actual self-destruction.

A third of these involved an elderly pilot (seventy) who stalled out proceeding downwind while initiating a 360 degree pattern turn after receiving a red light from a temporary tower during a windy day. The post mortem examination revealed a blood alcohol of $35 \mathrm{mg} \%$, which, in view of the circumstances of the accident, the age of the pilot (aging decreases the resistance of an individual to most pharmacologic agents, including alcohol), and the other considerations discussed previously in this paper, was felt to have played a major role in bringing about the accident.

It should be noted here, that the currency of a given pilot (in terms of recent flight experience), the flight history of the pilot (in terms of quality of training and over-all flight experience, knowledge and competency), and the familiarity of the pilot with the aircraft and geographic area involved, bear importantly on the degree of adverse effects of alcohol on flight proficiency.

Those pilots who fly daily, as, for example, the previously mentioned air mail pilots, become so familiar with their aircraft, that they can compensate up to a point for small amounts of alcohol. For example, the famous Australian pilot, Sir Charles Kingsford-Smith, reports that during his 1931 attempt to set an Australia to England speed record, he "took an occasional nip of brandy-which kept me going". ${ }^{\circ}$ Pilots who, as often found in the business-man pilot and pleasure pilot categories of general aviation, fly one or two hours a month, or who have just "stepped up" in aircraft class, are very susceptible to flight performance impairment through alcohol. It is not unusual to find that in certain of the latter two groups of pilots, each flight is an adventure in the sober state, much less the ethanolized state.

The paper by Drs. Albers and Harper bears out this latter observation, in that they find that only three of the 56 positive blood alcohol cases had current instrument ratings. They also found that the positive alcohol group peaked at 300 
hours, a relatively low flight experience. Sixteen percent had 100 hours or less, a factor two times that for the 100 hours or less pilot experiencing a fatal accident not involving alcohol. The alcohol group also had twice as many cases at night than did non-alcohol groups. Also, more than half of the accidents involved "loss of control," including stall-spin accidents, and twenty percent involved "struck object" accidents.

Drs. Albers and Harper conclude that alcohol adversely affects flying performance at levels considerably below those which adversely affect driving. They use $15 \mathrm{mg} \%$ as the critical level where adverse effects may begin to appear. Preliminary analyses of a current series of studies at the Civil Aeromedical Research Institute, confirm the critical nautre of the $15 \mathrm{mg} \%$ level. Also, the combination of small amounts of alcohol with various hypoxia levels (starting at 8,000 feet) is under scrutiny. The tests used determine fine coordination, decision capabilities, flicker fusion levels and involuntary eye movements (nystagmus). An interdisciplinary team consisting of psychologists, physiologists and physicians, is accomplishing the studies, which are conducted at CARI with special apparatuses in a large altitude chamber.

It is to be stressed that the great majority of general aviation pilots are mature and dependable individuals, and operate their aircraft safely. However, through lack of understanding, or proper education, or character, a small number of the total pilots, undertake flights while under the influence, and a certain percent of these have accidents. A certain number of episodic drinkers become pilots, and, sooner or later, some of these undertake to fly during a spree. Also, a minute number of pilots, as is true in all groups, become true alcoholics, and some of these sooner or later decide to make a flight while drinking. In the interest of safety, alcoholism is disqualifying for an airman's medical certificate as issued by the FAA.

\section{Selected Comments}

Part 91 of the Federal Aviation Regulations, "General Operating and Flight Rules", provides that no person may act as a crewmember (or pilot in command) of a civil aircraft while under the influence of intoxicating liquor. ${ }^{17}$ The enforcement of this regulation is difficult, and its ultimate impact must derive from the individual pilot. It should be noted that the individual pilot must be alert to sources of ethyl alcohol other than liquor (cough medicine, tonies, etc.). A good rule to follow is that if one is sick enough to require these substances, he is too sick to fly at the time.

Another matter of concern, is the possibility of "endogenous alcohol" being formed in the tissues during the period following death." Also, one must be certain that the laboratory accomplishing the blood alcohol test is using a reliable method.

Since the days of the English Admiral, Edward Vernon, who wore a grogram coat and was known as "old Grog" (who ordered the sailor's rum diluted, an event leading to any intoxicating liquor called "grog"), it has become increasingly apparent that we will live with machinery, particularly vehicular machinery, and specifically aircraft, much better if we go easy with alcohol. A good rule is to allow twenty four hours from "bottle to throttle", although fifteen should be sufficient following light indulgence (3 ounces). Eight hours is the minimum time allowed by the Federal Aviation Agency for its own pilots before flight can be undertaken following alcohol consumption (Flight Standards Handbook 4040.1, Paragraph 2.111). This rule has worked with apparent safety, within the context of FAA flight activities and through the exercise of judgment by FAA pilots.

A recent article on automobile accidents, is consistent in its conclusions concerning drivers with the conclusions in this paper concerning pilots. ${ }^{18}$ The article reports that $50 \mathrm{mg} \%$ blood alcohol levels and lower have a deleterious effect on driving performance and that alcohol is a contributing or critical factor in 25 to $50 \%$ of fatal automobile accidents.

An active and agressive airman education program concerning the potentially disastrous consequences of mixing alcohol and flying, even at very low levels of alcohol, can potentially result in a significant reduction in the annual toll of life taken through light aircraft accidents. For those who would consider combining flying with drinking, it should be emphasized that the beauty of flight, and the pleasures of flying, are, of themselves, sufficiently satisfying (for many even exhilarating), to preclude any necessity of combining alcohol with flying. 


\section{Conclusions}

1. One ounce of whiskey or one beer ingested during the period which immediately precedes flight planning prior to undertaking a flight can cause a significant impairment in airmanship.

2. Present evidence indicates that about one third of the fatal accidents now being experi- enced in civil light aircraft today are facilitated directly or indirectly by ethyl alcohol ingestion.

3. Within the context of this paper, an aggressive education program for general aviation airmen is indicated, and represents one of the major areas within which a substantial reduction may be accomplished in the incidence of light aircraft accidents.

\section{REFERENCES}

1. Schmidt, Wolfgang, Smart, Reginatd G., and PopHAM, RoBent E.: "The Role of Alcoholism in Motor Vehicle Accidents", Traffic Safety: 4-6, December 1962, p. 21.

2. Smith, H. W., Popham, R. E.: "Blood Alcohol Levels in Relation to Driving", Journal of the Canadian Medical Association: 65, 1951, pp. 325-328.

3. Bert, Patul : Barometric Pressure, 1877, Translation by Hitchcock, M. A. and Hitchcock, F. A., College Book Company, Columbus, Ohio, 1943, pp. 1-1055.

4. Harper, Charies R., and Albers, William R.: "Alcohol and General Aviation Accidents", Aerospace Medioine, 35 :5, May 1964, pp. 462-464.

5. Federal Aviation Agency: "Alcohol and Aircraft Accidents", Medical Nenssletter, Volume 3, Number 7, July 1962, pp. 7-8.

6. Kingsford-Smith, Sir Chartes: My Flying Life, The Aviation Book Club, London, 1939, p. 210.

7. Heise, Herman A.: "Drugs-Alcohol-and Flying": The Flying Physician, Volume 8, Number 1, January 1964, pp. 11-15.

8. War Department: Air Service Medical, U.S. Government, Printing Office, 1919, pp. 1-446.

9. Armstrong, Harry G.: Principles and Practice of Aviation Medicine, Bailliere, Tindall and Cox, London, 1939, pp. 1-496.
10. KAFKa, M. MARTYN : Flying Health, Military Service Publishing Company, Harrisburg, Pennsylvania, 1942, pp. 1-248.

11. McFarland, Ross A.: Human Factors in Air Transportation, McGraw-Hill Book Company, Inc., New York, 19533, pp. 1-830.

12. Masters, RICHaRd L.: "The Effects of Alcohol and Hypoxia on the Heterophorias", Aeromedical Reviews, Review 2-64, U.S.A.F. School of Aerospace Medicine, February 1964, pp. 1-22.

13. Smith, Dran C.: By the Seat of My Pants, Little, Brown and Company, Boston, 1961, p. 141.

14. Jordanoff, Assen: Safety in Flight, Funk and Wagnalls Company, New York, 1941, p. 127.

15. Conley, Cratre: "Five Drinking Pilots Died in Crashes Last Year", The Daily Oklahoman, January 8, 1964, p. 12.

16. VAJDA, S.: "Theory of Games", The World of Mathematics, Volume II, Simon and Shuster, New York, 1956 , p. 1285.

17. Federal Aviation Agency: "General Operating and Flight Rules", Code of Federal Regulations, Part 91, Title 14, January 1, 1963.

18. Goldstein, LeON G.: "Human Variables in Traffic Accidents: A Digest of Research", Traffic safety, Volume 8, No. 1, March 1963, pp. 26-31. 
Levels of Alcohol in Relation to Signs and Symptoms

Reference: Kurt M. Dubowski, Ph.D., FAIC

University of Oklahoma

Medical Center

Oklahoma City, Oklahoma

Member, Committee on Tests for Intoxication

National Safety Council

ILLUSTRATION I

\begin{tabular}{|c|c|c|c|}
\hline $\begin{array}{l}\text { EThYL ALCO } \\
\text { Per Cent } \\
\text { Blood }\end{array}$ & $\begin{array}{l}\text { OL LEVEL } \\
\text { y Weight } \\
\text { Urine }\end{array}$ & $\begin{array}{c}\text { STAGE } \\
\text { OF } \\
\text { ALCOHOLIC } \\
\text { INFLUENCE } \\
\end{array}$ & $\begin{array}{c}\text { CLINICAL } \\
\text { SIGNS/SYMPTOMS }\end{array}$ \\
\hline $\begin{array}{l}0.01-0.05 \\
(10-50 \mathrm{mg} \%)\end{array}$ & $0.01-0.07$ & Sobriety & $\begin{array}{l}\text { No apparent Influence } \\
\text { Behavior nearly normal by ordi- } \\
\text { nary observation } \\
\text { Slight changes detectable by } \\
\text { special tests }\end{array}$ \\
\hline $\begin{array}{l}0.03-0.12 \\
(30-120 \mathrm{mg} \%)\end{array}$ & $0.04-0.16$ & Euphoria & $\begin{array}{l}\text { Mild euphoria, sociability, talk- } \\
\text { ativeness } \\
\text { Increased self-confidence; de- } \\
\text { creased inhibitions } \\
\text { Diminution of attention, Judgment, } \\
\text { and control } \\
\text { Loss of efflciency in finer } \\
\text { performance tests }\end{array}$ \\
\hline $\begin{array}{l}0.09-0.25 \\
(90-250 \mathrm{mg} \%)\end{array}$ & $0.12-0.34$ & Excitement & $\begin{array}{l}\text { Emotional instability; decreased } \\
\text { inhibitions } \\
\text { Loss of critical judgment } \\
\text { Impairment of memory and compre- } \\
\text { hension } \\
\text { Decreased sensitory response; in- } \\
\text { creased reaction time } \\
\text { Some muscular incoordination }\end{array}$ \\
\hline $\begin{array}{l}0.18-0.30 \\
(180-300 \mathrm{mg} \%)\end{array}$ & $0.24-0.41$ & Confusion & $\begin{array}{l}\text { Disorientation, mental confusion; } \\
\text { dizziness } \\
\text { Exaggerated emotional states } \\
\text { (fear, anger, grief, etc.) } \\
\text { Disturbance of sensation (diplopla } \\
\text { etc.) and of perception of color, } \\
\text { form, motion, dimensions } \\
\text { Decreased pain sense } \\
\text { Impalred balance; muscular inco- } \\
\text { ordination; staggering gait, slur- } \\
\text { red speech }\end{array}$ \\
\hline $\begin{array}{l}0.27-0.40 \\
(270-400 \mathrm{mg} \%)\end{array}$ & $0.37-0.54$ & Stupor & $\begin{array}{l}\text { Apathy; general Inertia, approach- } \\
\text { lng paralysis } \\
\text { Markedly decreased response to } \\
\text { stimuli } \\
\text { Marked muscular incoordination; in } \\
\text { ability to stand or walk } \\
\text { Vomiting; incontinence of urine } \\
\text { and feces } \\
\text { Impaired consciousness; sleep or } \\
\text { stupor }\end{array}$ \\
\hline $\begin{array}{l}0.35-0.50 \\
(350-500 \mathrm{mg} \%)\end{array}$ & $0.47-0.67$ & Coma & $\begin{array}{l}\text { Complete unconsciousness; coma; } \\
\text { anesthesia } \\
\text { Depressed or abolished reflexes } \\
\text { Subnormal temperature } \\
\text { incontinence of urine and feces } \\
\text { Embarrassment of circulation and } \\
\text { respiration } \\
\text { Possible death }\end{array}$ \\
\hline $\begin{array}{l}0.45+ \\
(450 \mathrm{mg} \%)\end{array}$ & $0.60+$ & Death & Death from respiratory paralysis \\
\hline
\end{tabular}




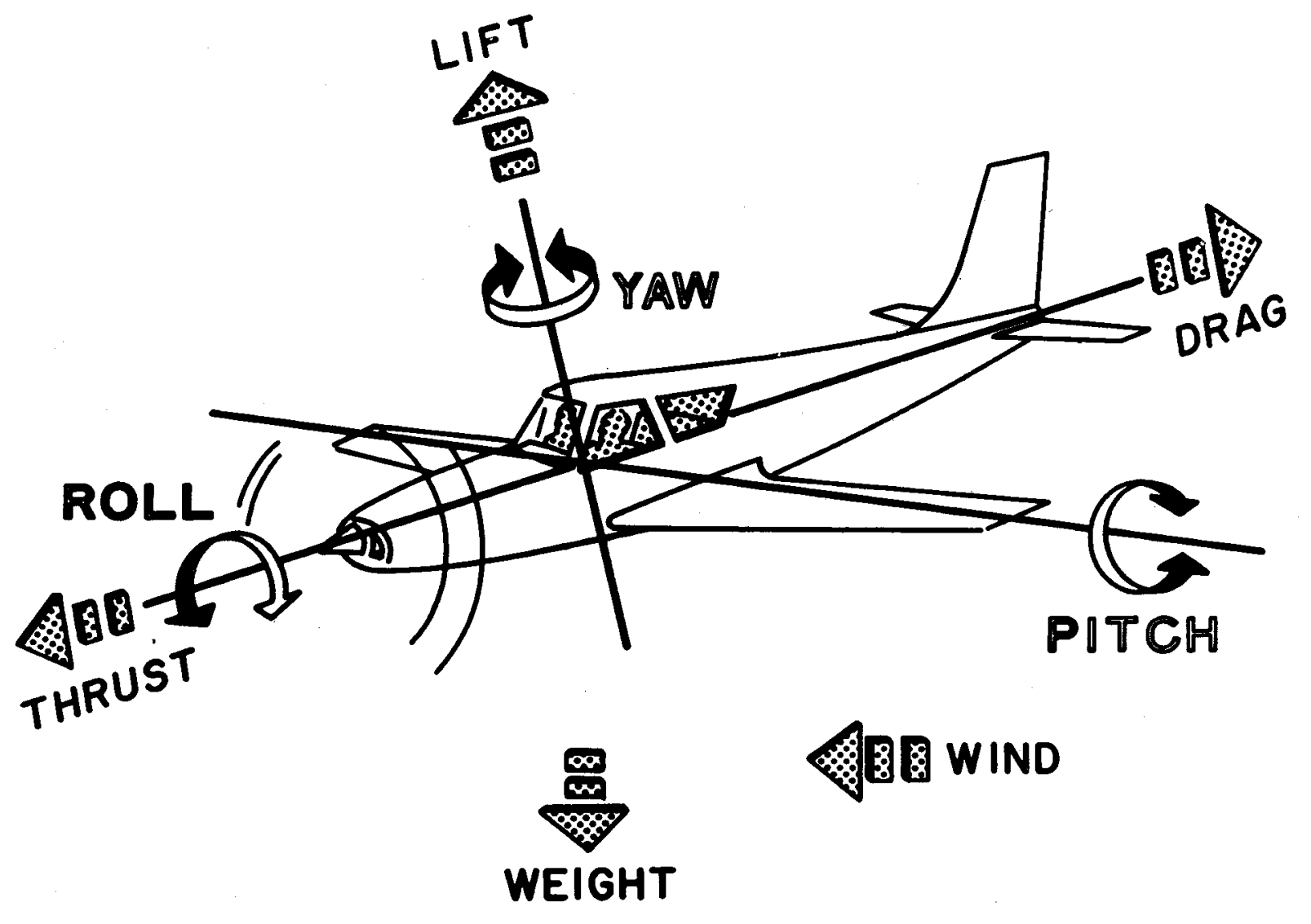

\section{ILLUSTRATION II}

Depicted above are certain key features of flight that determine the nature of the pilot's tasks. Three dimensional travel requires considerations beyond those specific to driving or yachting. For example, the pilot must watch his stall speed, red line speed, wind drift, and navigation procedures. He must coordinate roll, pitch and yaw, and manage various controls, including mixture and flaps. He must exercise a high degree of judgment, especially with respect to weather conditions, and must remain at a level of alertness sufficient to meet emergencies. These various requirements are adversely affected by acutely ingested alcohol. 
